\title{
On-line breath analysis of volatile organic compounds as a method for colorectal cancer detection
}

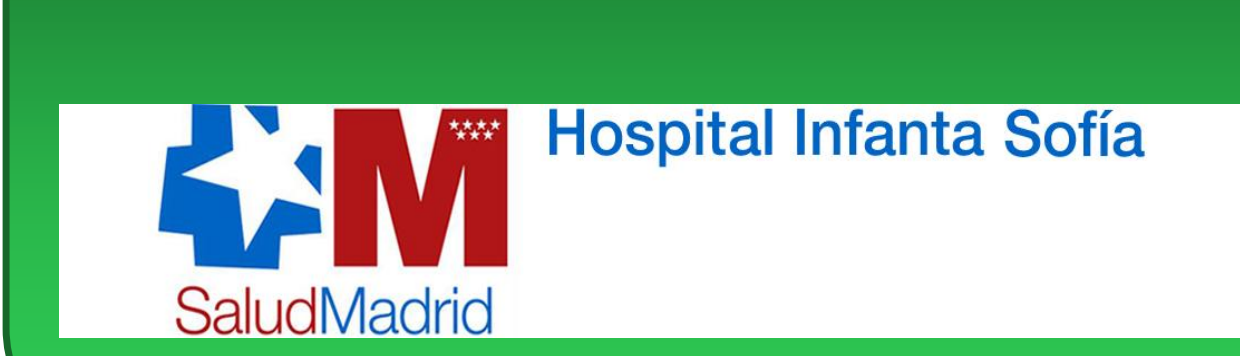

Francisco Zambrana', Ana Herrero², Guillermo Vidal-de-Miguel'2, Gonzalo Bailador ${ }^{3}$, Ernesto Criado², Carmen Sánchez-Ávila², Isabel Marquina ${ }^{6}$, María Sereno ${ }^{1}$, César Gómez-Raposo', Mirian

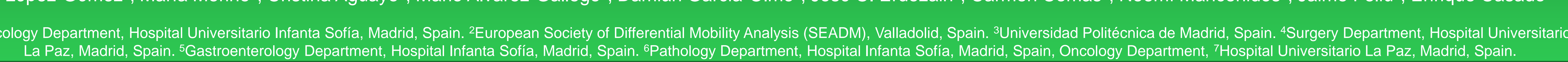

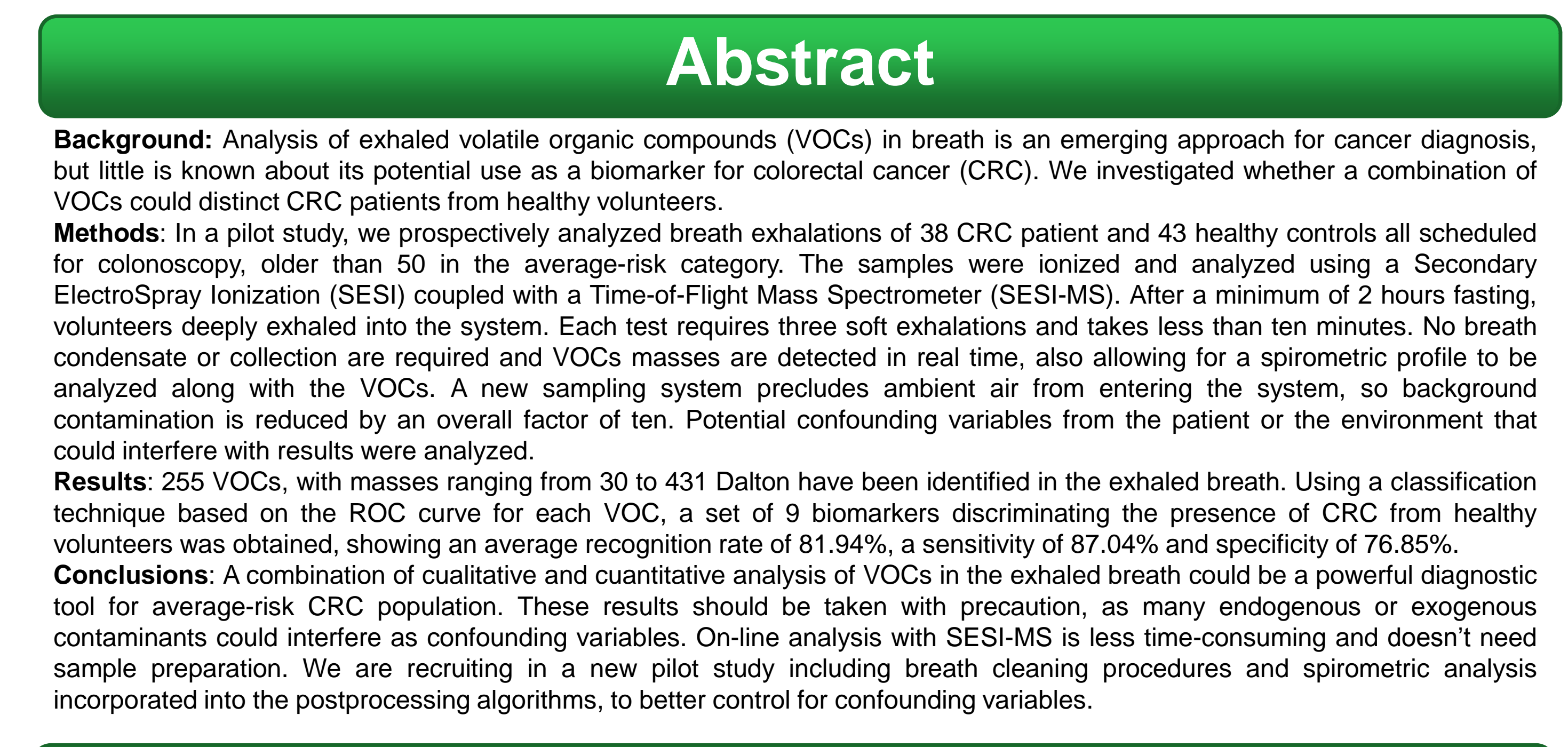

Background

CRC is one of the most common cancers in the Western world, with high incidence and mortality. Slow progression from adenoma to carcinoma and high patient survival in case of early detection maks

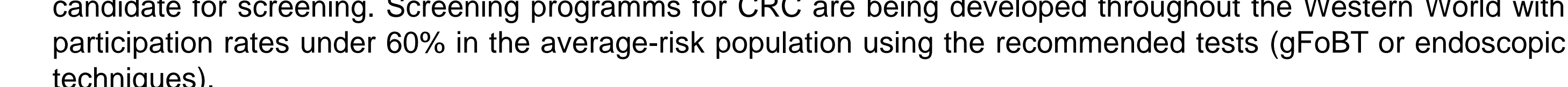

There are somes evidence supporting a different pattern of VOCs in breath in cancer patients, due to the difiterent

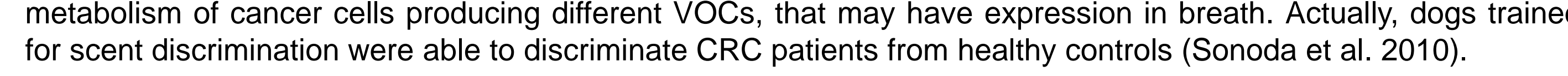

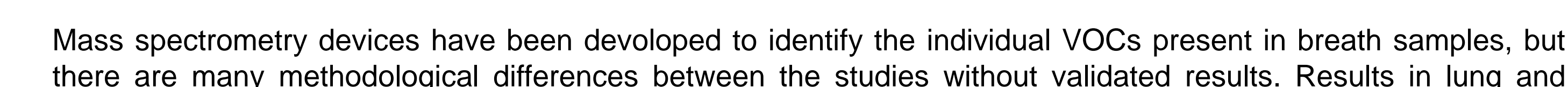

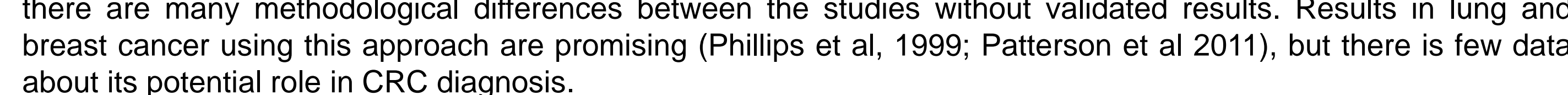

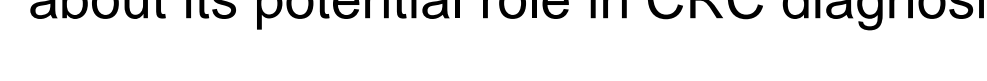
Along with htis, breath analysis of VOCs could be an easy and very acceptable test to increase the efficieincy of a
population-based screening program.

\section{Objectives}

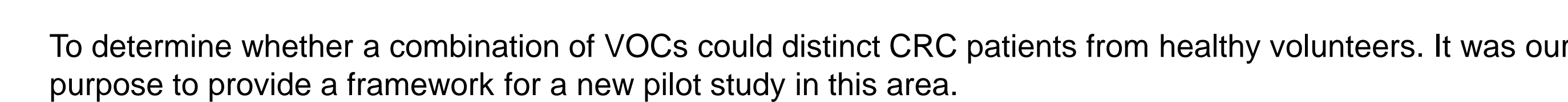

\section{Methods}

Demographics. Prospectively enrolled 38 CRC patients (all AJCC stages) and 43 heathy yolunteers, diagnosed
with colonoscopy.

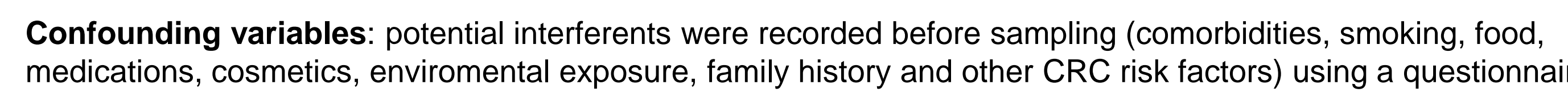
Breath sample: after 2 hours tasting volunteers exhaled into the system directly, without collection of breath in ary

Mass spectrometry system: Secondary ElectroSpray lonization (SESI) coupled with a Time-off-Fight Mass
Spoctrometer (SESS-MS)

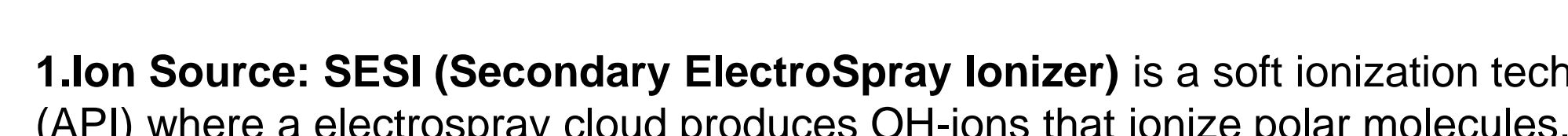

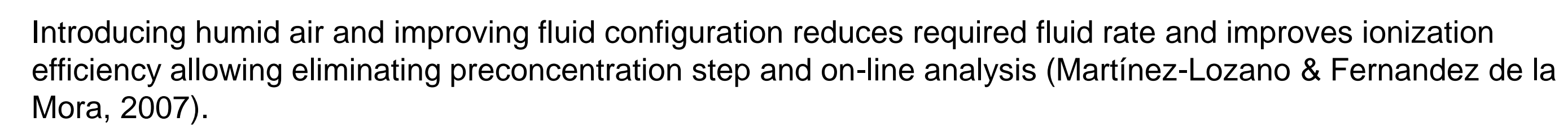

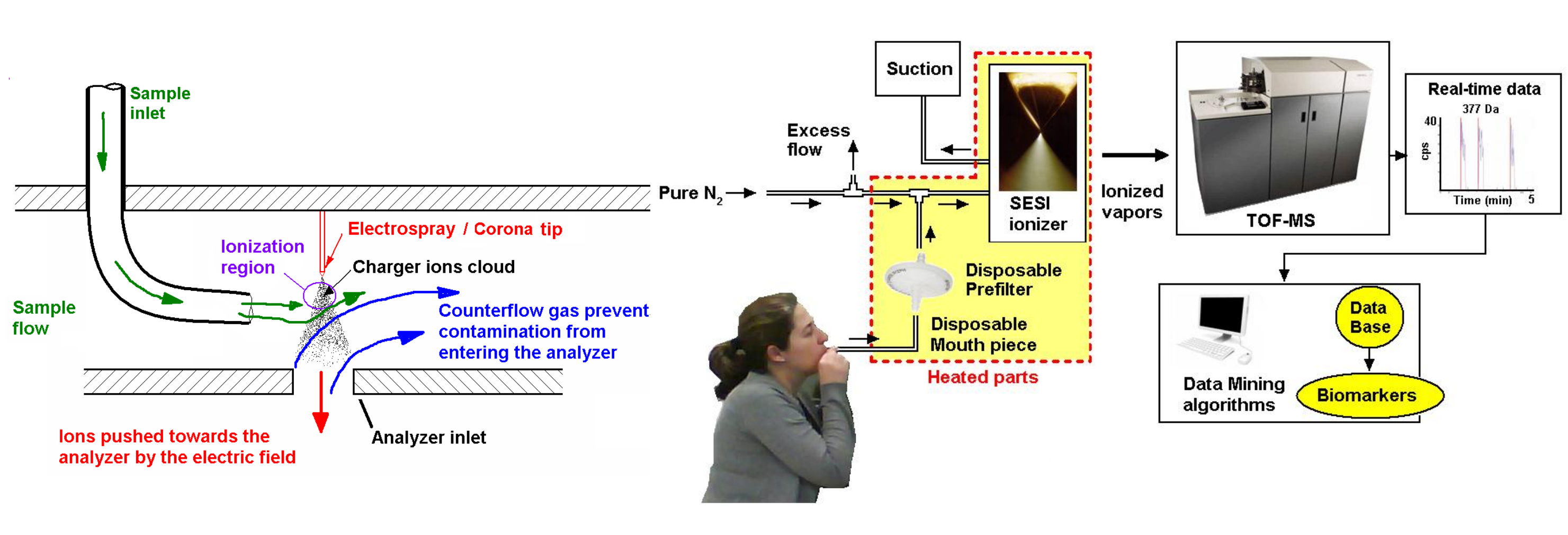

2.Mass analyzer: Quadruple time-of-filight mass spectrometer (QqTOF-MS).

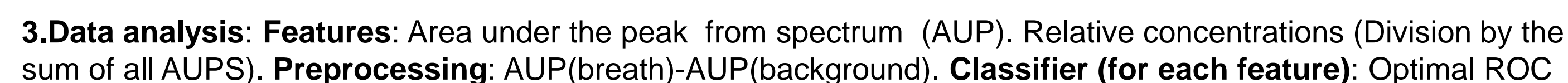

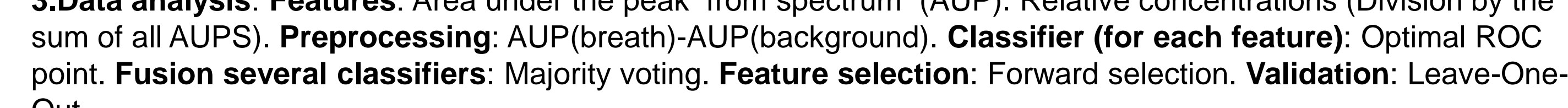
out.

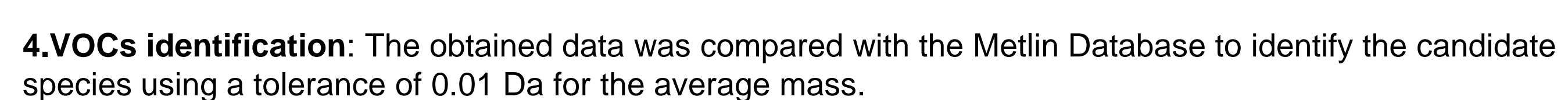

Results

255 VOCs, with masses ranging from 30 to 431 Dalton have been identified in the exhaled breath.

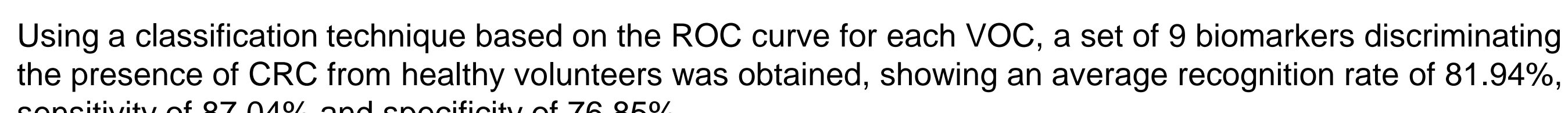
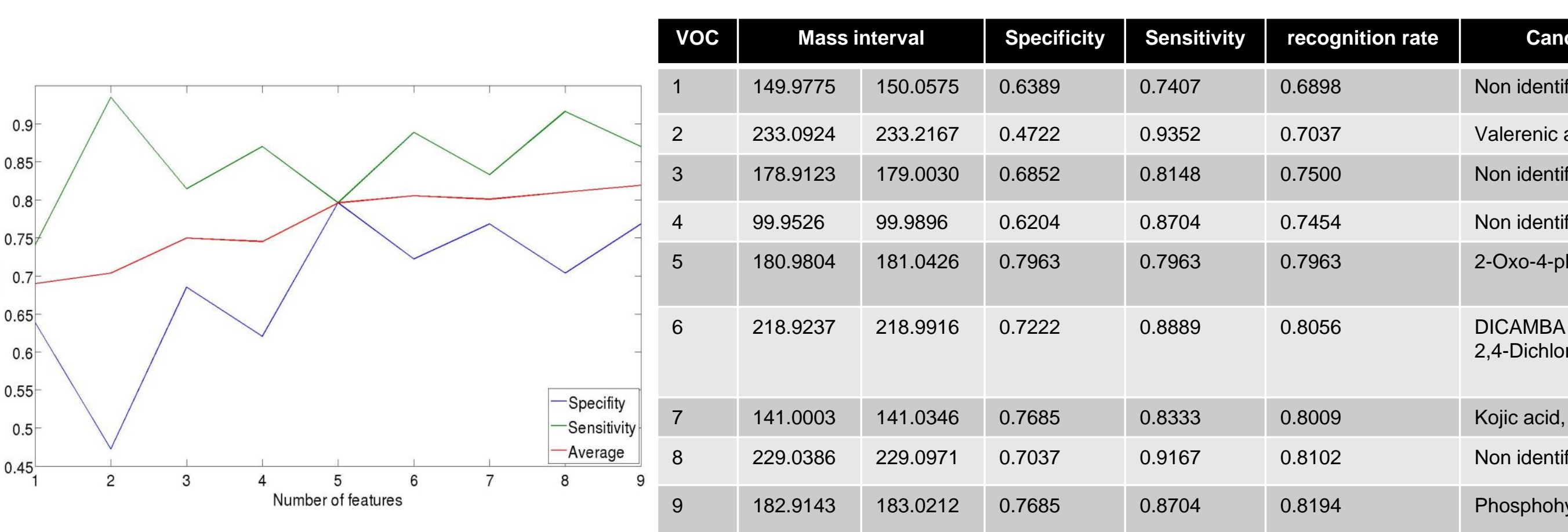

Atthough these results are quite promising, we have discovered that some of these variables present a
lemporal evoulution which may be produced by contaninants in the envivionment. Therefore these results should be taken with caution.

\section{Conclusions}

SESI-based analysis shows high sensitivity for the discovery of candidate biomarkers in breath and allows on-III Species coming from the inhaled air and those related to the long term distribution seem to be the main
conotionning variable to control. Dessite these, vverall sensitivity and specificity results are encouraging to pursue invesigating the potential use
of breath analysis tor detectivg CRC.

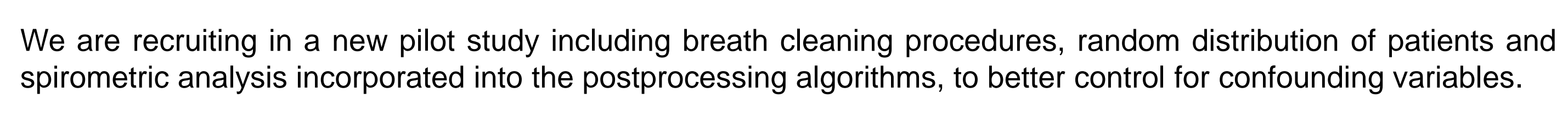

References

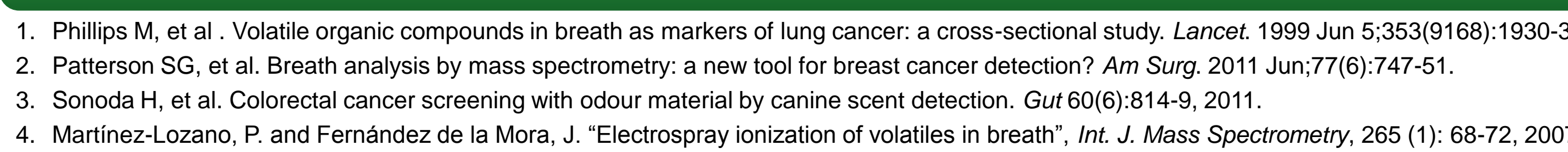

